\title{
Postpericardiotomy Syndrome after Cardiac Operations
}

\author{
Shi-Min Yuan \\ Division of Cardiac Surgery, Department of Cardiothoracic Surgery, The First Hospital of Putian, Teaching Hospital, \\ Fujian Medical University, Chengxiang District, Fujian Province, China
}

\begin{abstract}
The postpericardiotomy syndrome (PPS) is an important cause of morbidity and mortality following heart operation. This systematic review reviewed the literature regarding PPS. It was found to occur on day $18.3 \pm 15.9$ after cardiac operations, most often after coronary artery bypass grafting, and mitral valve replacement. The most common symptoms were new/worsening pericardial effusions, pleuritic chest pain, and fever. The inflammation markers, such as C-reactive protein and erythrocyte sedimentation rate, were found to increase significantly in each patient who had these parameters examined. The subjects were managed conservatively in $472(83.5 \%)$ patients, by surgical pericardial drainage in 85 $(15.0 \%)$ patients, by thora-/pericardio-centesis in $3(0.5 \%)$ patients, and were under surveillance without being treated in $5(0.9 \%)$ patients. Conservative treatment was likely to be associated with a higher recovery rate. Surgical trauma and cardiopulmonary bypass trigger the systemic inflammatory response, which results in antiheart autoantigen release, and the deposited immune complex could be found in the pericardial, pleural, and lung tissues, thereby provoking the occurrence of PPS. Therapeutic options for the refractory cases are long-term oral corticoids or pericardiectomy. Surgical intervention was warranted in $2.6 \%$ of the cases due to cardiac tamponade.
\end{abstract}

Key Words: Etiology, Pericardial effusion, Postpericardiotomy syndrome.

How to cite this article: Yuan SM. Postpericardiotomy syndrome after cardiac operations. J Coll Physicians Surg Pak 2020; 30(1):62-66.

\section{INTRODUCTION}

As a surgical complication, the postpericardiotomy syndrome (PPS) often complicates the heart operations, and the documented incidence ranged from $1 \%$ to $40 \% .1$ PPS has been regarded as an important cause of death of cardiac surgical patients, and it can lead to the development of adverse events, such as obstruction of the graft vessels and massive tamponade. ${ }^{2}$ There have been conflicting results concerning the underlying cardiac operations that lead to the development of PPS. In the early years, it was reported that congenital atrial septal defect repair was associated with an increased incidence of PPS in comparison to alternative cardiac surgical procedures. ${ }^{3}$ In recent years, it was observed that PPS developed more often after coronary artery bypass grafting and heart valve procedures. ${ }^{4}$ It was also observed that PPS might occur after pacemaker implantation ${ }^{5}$, coronary perforation during balloon angioplasty $^{6}$, and lung operations. . $^{7,8}$ The pathophysiology of PPS is still uncertain in spite of the common view that heart operation itself along with the utilisation of extracorporeal circulation triggers a systemic inflammation that further progresses into PPS. ${ }^{9}$ In general,

Correspondence to: Shi-Min Yuan, Division of Cardiac Surgery, Department of Cardiothoracic Surgery, The First Hospital of Putian, Teaching Hospital, Fujian Medical University,

Chengxiang District, Fujian Province, China

E-mail: shiminyuan@126.com

Received: March 21, 2019; Revised: May 20, 2019;

Accepted: June 19, 2019 there are many unanswered questions regarding the etiology, diagnosis, and treatment of PPS after cardiac operation. The aim of this systematic review was to give an overview of PPS and discuss its etiology, diagnosis, and treatment.

\section{METHODOLOGY}

The present study adhered to the PRISMA guidelines. Publications were systematically searched in the PubMed, Highwire Press, and the Cochrane Library databases between January 2000 and December 2018. The MeSH terms and keywords used to identify articles included "postpericardiotomy syndrome", "cardiac surgical procedures", "coronary artery bypass grafting", "valve replacement", "aortic valve replacement", "mitral valve replacement", "aorta operation", "atrial septal defect", and "congenital heart defect". The screening of the bibliographic references helped in completing the literature retrieval. Sixty-four articles were found related to the topic and keywords in the literature search; and 20 articles, which met the inclusion and exclusion criteria during preliminary assessment, were included in the review. The exclusion criteria were: lack of patient information $(n=20)$, cardiovascular effect of colchicine $(n=9)$, risk factors of PPS $(n=4)$, prophylaxis of PPS $(n=3)$, pericardial effusions $(n=3)$, pericardial diseases $(n=1)$, PPS after pectus excavatum repair $(n=1)$, PPS due to pacemaker implant $(n=1)$, cardiac tamponade $(n=1)$, and non-postcardiotomy cardiogenic shock $(n=1)$. The flow chart of study selection process is shown in Figure 1. 
The data independently extracted from each study were the study population, demographics, clinical diagnosis, surgical procedures, timing of occurrences of PPS, therapeutic strategies and effects, and patients' outcomes.

IBM SPSS Statistics version 22.0 was used for the statistical analyses. The measurement data were depicted in a format of mean value \pm standard deviation. They were tested with t-test. The qualitative variables were described as frequency and percentage, which were tested with Fisher exact test. The $p<0.05$ was regarded as having a statistical significance.

\section{RESULTS}

A total of 20 articles with 661 patients were included. 1,10-28 The patients were at the age of $43.1 \pm 24.3$ (range, 3.8-81; median, 47$)$ years $(n=15)$. Of them, gender was described for 410 patients: $271(66.1 \%)$ were male and $139(33.9 \%)$ were female patients $\left(\chi^{2}=85.0, p<0.001\right)$.

The dominant symptom was new/worsening pericardial effusion (Table I). The amount of pericardial effusions was described for 277 patients: it was small, moderate, and large in $99(35.7 \%), 11,13,16,23,2493$ (33.6\%), 11,21,23,24 and $85(30.7 \%)$ patients, 1,10,11,14,15,23-26 respectively.

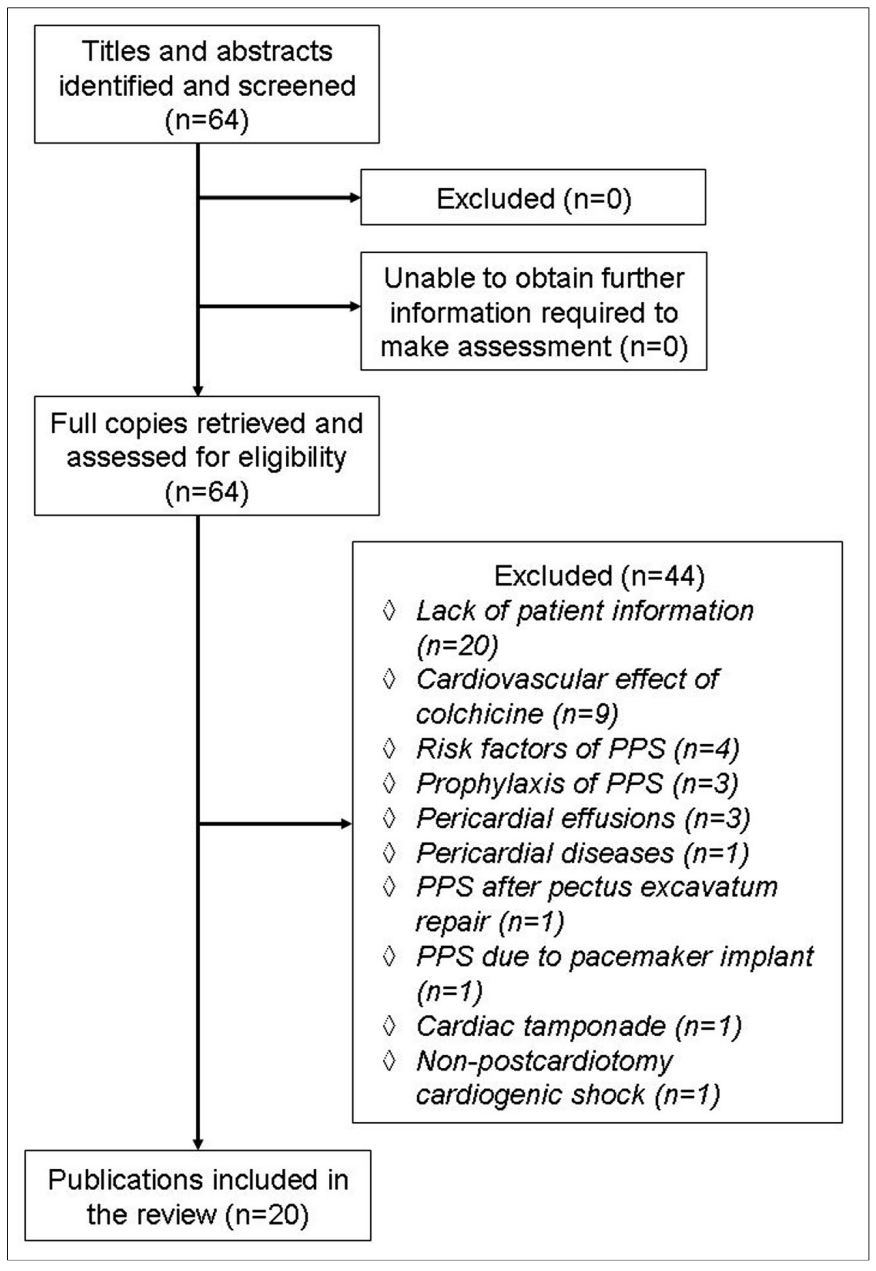

Figure 1: The flow chart of study selection process.
Tamponade occurred in $85(85 / 661,12.6 \%)$ patients. ${ }^{10-12,14,}$ 17,20,24,25 PPS occurred on day $18.3 \pm 15$.9 (range, 2-60; median, 14) ( $n=15)$ after cardiac operations. 1,10,11,13-18,20$22,25,26,28$ The pleural effusions could occur on the left, 13 right, 22 or bilateral sides, $10,16,25,26$ and the amount of pleural effusions might be large.13,26 The underlying cardiac operations that caused PPS were reported for 483 patients. Of them, coronary artery bypass grafting was the operation that led to PPS the most often, followed by mitral valve replacement (Table II).

C-reactive protein was reported for 84 patients, and it was elevated in all 84 patients $1,11,17,19-21,25,27$ with a mean of $15.5 \pm 12.8 \mathrm{mg} / \mathrm{dL}(\mathrm{n}=4)$. Erythrocyte sedimentation rate was reported for 87 patients, and it was elevated in all 87 patients, $1,11,18,20,21,27$ too, with a mean value of $35.4 \pm 9.0 \mathrm{~mm} / \mathrm{hour}(\mathrm{n}=4)$. The diagnosis of PPS could rely on the pleural/pericadial effusion by the medical imaging, such as chest radiography, ${ }^{10,13}$ echocardiography, 10,13 right heart catheterisation, 26 computed tomography, 10 and magnetic resonance imaging. ${ }^{25}$

The patients were on a mean follow-up of $15.8 \pm 25.5$ (range, 1.25-54; median 4) months $(n=4)$.

The treatment of choice was described for 565 patients. The patients were managed conservatively in 472 $(83.5 \%)$ patients, by surgical pericardial drainage in 85 $(15.0 \%)$ patients, by thora-/pericardio-centesis in 3 $(0.5 \%)$ patients, and were under surveillance without

Table I: Clinical presentations of 313 patients from 14 reports.

\begin{tabular}{|c|c|}
\hline Clinical presentation & n $(\%)$ \\
\hline Pericardial effusion (new/worsening) ${ }^{10,11}$ & $212(67.6)$ \\
\hline Pleuritic chest pain $11,13,16,18,20,21,25$ & $154(49.2)$ \\
\hline Fever10,11,13,18,20,25 & $141(45.0)$ \\
\hline Pleural effusion10,11,18 & $100(31.9)$ \\
\hline Pericardial friction rub11,18 & $50(16.0)$ \\
\hline Dyspnea / shortness of breath10,15,20-22,25,26 & $32(10.2)$ \\
\hline Friction rub20 & $4(1.3)$ \\
\hline Elevated erythrocyte sedimentation rate ${ }^{18}$ & $3(1.0)$ \\
\hline Palpitation 17,21 & $2(0.6)$ \\
\hline Pleural friction rub18 & $2(0.6)$ \\
\hline Decreased exercise tolerance 26 & $1(0.3)$ \\
\hline Heart failure ${ }^{14}$ & $1(0.3)$ \\
\hline Malaise ${ }^{17}$ & $1(0.3)$ \\
\hline Night sweats 17 & $1(0.3)$ \\
\hline Pericardial effusion18 & $1(0.3)$ \\
\hline
\end{tabular}

Table II: The underlying cardiac operations that caused PPS in 483 patients.

\begin{tabular}{l|c}
\hline Underlying cardiac operation & $\mathrm{n}(\%)$ \\
\hline Coronary artery bypass grafting $11,13,15,18-21,25,26$ & $174(36.0)$ \\
Mitral valve replacement11,16,19 & $90(18.6)$ \\
Aortic valve replacement10,11,19 & $85(17.6)$ \\
Aortic surgery $11,17,23$ & $73(15.1)$ \\
Atrial septal defect closure $1,23,28$ & $33(6.8)$ \\
Surgery for congenital heart defect, unspecified 19,27 & $23(4.8)$ \\
Mitral and aortic valve replacements, coronary artery & \\
bypass grafting 22,23 & $4(0.8)$ \\
Heart transplantation 14 & $1(0.2)$ \\
\hline
\end{tabular}


Table III: Pharmaceutical therapy in 521 patients with PPS.

\begin{tabular}{|c|c|}
\hline Pharmaceutical therapy & $\mathrm{n}(\%)$ \\
\hline NSAIDs & $379(59.2)$ \\
\hline Aspirin 11,28 & $180(47.5)$ \\
\hline Ibuprofen $1,11,17$ & $119(31.4)$ \\
\hline Diclofenac 23 & $63(16.6)$ \\
\hline NSAIDs, unspecified $20,21,26$ & $16(4.2)$ \\
\hline Indocin $(75 \mathrm{mg} / \text { day })^{16}$ & $1(0.3)$ \\
\hline Corticosteroids & $197(30.8)$ \\
\hline Prednisone ${ }^{11,20,28}$ & $111(56.3)$ \\
\hline Hydrocortison ${ }^{12}$ & $84(42.6)$ \\
\hline Corticosteroids, unspecified 14,25 & $2(1.0)$ \\
\hline Colchicine ${ }^{11,15,20,21,26}$ & $63(9.8)$ \\
\hline Antiinflammatory, unspecified 25 & $1(0.2)$ \\
\hline
\end{tabular}

Table IV: Patient outcomes with different treatments.

\begin{tabular}{l|c|c|c|c}
\hline Outcome & Recovered & Improved & Recurred & Complicated \\
\hline Conservative & $143(97.9)$ & $1(0.7)$ & $1(0.7)$ & $1(0.7)$ \\
Surgical & $2(40)$ & $1(20)$ & $2(40)$ & \\
Centesis & $3(100)$ & & & \\
Untreated & $5(100)$ & & & \\
$\chi^{2}$ & 45.0 & & & \\
p-value & $<0.001$ & & & \\
\hline
\end{tabular}

being treated in $5(0.9 \%)$ patients. The treatment regimen with nonsteroidal antiinflammatory drug, corticosteroids, and colchicine are popularly accepted (Table III). Conservative treatment was likely to be associated with a higher recovery rate (Table IV).

The outcomes of 220 patients were known: 191 (86.8\%) recovered fully, $26(11.8 \%)$ recurred, $2(0.9 \%)$ were improved, and $1(0.5 \%)$ was complicated.

\section{DISCUSSION}

The etiology of PPS is unknown. It has been proposed that the surgical trauma and cardiopulmonary bypass trigger the systemic inflammatory response.29 The inflammatory reactions result in antiheart autoantigen release, and the deposited immune complex could be found in the pericardial, pleural, and lung tissues. ${ }^{30,31} \mathrm{~A}$ direct correlation has been noted between the antiheart autoantibodies and PPS. 32 In addition, Engle et al. ${ }^{33}$ proposed that PPS was a disorder mediated by the immune reactions and induced by the viral infections. 33 Nevertheless, Webber et al. ${ }^{34}$ did not agree with the viewpoint in regard to the viral etiology of PPS. ${ }^{34}$

The most common symptoms of PPS are pleuritic chest pain, low fever, pleural/pericardial rub, pericardial/pleural effusions, increased erythrocyte sedimentation rate and C-reactive protein values, and electrocardiographic alterations. ${ }^{4}$ Severe consequences like tamponade, circulatory collapse, and pulmonary edema, seem to be less frequent. ${ }^{4}$ The febrile patients usually do not have any positive results in the laboratory tests as an evidence of infection and a need of antibiotic treatment. The inflammation biomarkers, such as C-reactive protein and erythrocyte sedimentation rate, are positive in each case undergoing a heart operation.11 The diagnosis of PPS can be difficult, and it should be firstly differentiated from alternative cardiopulmonary disorders including myocardial infarction, pulmonary embolism, and perioperative pericarditis. ${ }^{4}$ The long-term unhealed clinical presentations for weeks to months, following a heart operation and showing good responses to the antiinflammatory drugs, are helpful to establish the diagnosis of PPS. ${ }^{16}$

There has been no consensus about the underlying cardiac operations as the cause of PPS. Alraies et al.11 reported that PPS commonly occurred following coronary artery bypass grafting, aortic and mitral valve operations, and aorta repair. ${ }^{11}$ However, Chhabra and Chaubey 35 found that PPS was more common in patients undergoing valve operation in particular aortic valve replacement in comparison to coronary artery bypass grafting. This review revealed that PPS occurred most often after coronary bypass grafting than after other cardiac operations.

It was reported that PPS often developed 3-4 weeks after the cardiac operations. ${ }^{11}$ The present study disclosed that the PPS occurred at a mean of 18.3 days after the cardiac operation, which was similar to what has been reported in the literature. The risk factors for PPS occurrence after cardiac operation were patients at a younger age and an elevated C-reactive protein level on admission. 36

Transthoracic echocardiography is the golden standard for a definite diagnosis of PPS.12 At least two of the following criteria should be met for the establishment of the diagnosis of PPS: chest pain in exclusion of wound pain, subfebrility, leucocytosis with negative cultures, and contemporary electrocardiographical signs of pericarditis, or presence of pericardial friction rub, or pericardial effusion. ${ }^{12}$

The treatment regimens for PPS include nonsteroidal antiinflammatory agents, aspirin, corticosteroids, and colchicine. ${ }^{11}$

The popular treatment of choice for refractory PPS includes nonsteroidal antiinflammatory agents, steroids, and surgical pericardial window creation. ${ }^{37}$ The first line treatment of PPS is often the nonsteroidal antiinflammatory agents, such as including aspirin, indomethacin, and ibuprofen, etc. ${ }^{38}$ However, cortico-steroid treatment can be associated with a higher recurrence rate, and steroid dependency. ${ }^{39}$ Colchicine is not only a remedy of recurrent pericardial infection but also a preventive measure of PPS. Intravenous immunoglobulin is primarily used for the treatment of immunomediated diseases, and is also an alternative of treatment of PPS. ${ }^{28}$

An interventional measure is warranted in $31 \%$ of PPS patients. ${ }^{11}$ The therapeutic options for the refractory cases are long-term oral corticoids or pericardiectomy. A 
surgical intervention was warranted in $2.6 \%$ of the cases due to cardiac tamponade. ${ }^{12}$ Patients at an older age and the use of colchicine were proved to be the two factors decreasing the need of procedural interventions. ${ }^{11}$

It was suggested that preoperative corticosteroids have shown a significant reduction in the risk of developing PPS. 40 However, high-dose corticosteroids might be associated with an increased risk of cardiovascular disease and mortality. ${ }^{41}$ Moreover, Bunge et al. ${ }^{9}$ observed that the incidence of PPS after dexamethasone was compatible to placebo $(13.5 \%$ vs. $15.5 \%$ ), indicating that dexamethasone did not show any preventive effect to the development of PPS. In comparison, colchicine use during perioperative period (starting from 2-3 days prior to the heart operation to postoperative day 3 for consecutive 1 month) showed a promising effect to prevent from the occurrence of PPS. 42

\section{CONCLUSION}

PPS might be of an immune etiology due to the myocardial damage during cardiac operations and cardiopulmonary bypass. It often occurred on day 18.3 after the cardiac operations. The diagnosis of PPS depends on the typical clinical presentations. PPS is usually curable to nonsteroidal antiinflammatory drugs, such as aspirin, steroids, and colchicine. Therapeutic options for the refractory cases are long-term oral corticoids or pericardiectomy. Surgical intervention was warranted in $2.6 \%$ of the cases due to cardiac tamponade. Colchicine may be used before or after cardiac operations for a prophylaxic purpose of PPS.

\section{CONFLICT OF INTEREST:}

Authors declared no conflict of interest.

\section{AUTHOR'S CONTRIBUTION:}

SMY: Substantial contribution to the conception and design of the work; and the acquisition, analysis, and interpretation of data for the work; drafting the work and revising it critically for important intellectual content; final approval of the version to be published; agreement to be accountable for all aspects of the work in ensuring that questions related to the accuracy and integrity of any part of the work are appropriately investigated and resolved.

\section{REFERENCES}

1. Heching $\mathrm{HJ}$, Bacha EA, Liberman L. Post-pericardiotomy syndrome in pediatric patients following surgical closure of secundum atrial septal defects: Incidence and risk factors. Pediatr Cardiol 2015; 36:498-502.

2. Miller RH, Horneffer PJ, Gardner TJ, Rykiel MF, Pearson TA. The epidemiology of the postpericardiotomy syndrome: $A$ common complication of cardiac surgery. Am Heart J 1988; 116:1323-9.

3. Timmis GC, Gordon S, Ramos RG. Recurrent postpericardiotomy syndrome: Its protracted nature and association with atrial septal defects. Mich Med 1971; 70:539-42.
4. Imazio M, Brucato A, Rovere ME, Gandino A, Cemin R, Ferrua S, et al. Contemporary features, risk factors, and prognosis of the post-pericardiotomy syndrome. Am J Cardiol 2011; 108:1183-7.

5. Spindler M, Burrows G, Kowallik P, Ertl G, Voelker W. Postpericardiotomy syndrome and cardiac tamponade as a late complication after pacemaker implantation. Pacing Clin Electrophysiol 2001; 24:1433-4.

6. Escaned J, Ahmad RA, Shiu MF. Pleural effusion following coronary perforation during balloon angioplasty: An unusual presentation of the postpericardiotomy syndrome. Eur Heart $J$ 1992; 13:716-7.

7. Eguchi T, Yoshida K, Hamanaka K, Kurai M. Colchicine as an effective treatment for postpericardiotomy syndrome following a lung lobectomy. Interact Cardiovasc Thorac Surg 2010; 11:869-71.

8. Barbetakis N, Asteriou C, Kleontas A, Lafaras C. Post-pericardiotomy syndrome following lung cancer surgery. Interact Cardiovasc Thorac Surg 2010; 11:871.

9. Bunge JJ, van Osch D, Dieleman JM, Jacob KA, Kluin J, van Dijk D, et al. Dexamethasone for cardiac surgery (DECS) study group. Dexamethasone for the prevention of postpericardiotomy syndrome: A dexamethasone for cardiac surgery substudy. Am Heart J 2014; 168:126-31.e1.

10. Almendro Delia M, García Rubira JC, Sayago Silva I, Hidalgo Urbano R. Postpericardiotomy syndrome. Where is the catheter? Acute Card Care 2011; 13:243-4.

11. Alraies MC, AlJaroudi W, Shabrang C, Yarmohammadi H, Klein AL, Tamarappoo BK. Clinical features associated with adverse events in patients with post-pericardiotomy syndrome following cardiac surgery. Am J Cardiol 2014; 114:1426-30.

12. Bucekova E, Simkova I, Hulman M. Postpericardiotomy syndrome - post-cardiac injury syndrome. Bratisl Lek Listy 2012; 113:481-5.

13. Bujarski S, Guy E. Use of indwelling pleural catheter for recurrent pleural effusion due to postpericardiotomy Syndrome: A Case Report. J Bronchology Interv Pulmonol 2016; 23:160-2.

14. Charitos CE, Kontoyannis DA, Nanas JN. Postpericardiotomy syndrome during intensive immunosuppression after cardiac transplantation. Acta Cardiol 2000; 55:95-7.

15. Dainese L, Cappai A, Biglioli P. Recurrent pericardial effusion after cardiac surgery: The use of colchicine after recalcitrant conventional therapy. J Cardiothorac Surg 2011; 6:96.

16. Edriss H, Lorenzana J, Nugent K. Does cardiac surgery vasoplegia trigger the postpericardiotomy syndrome? Am J Med Sci 2015; 349:463-5.

17. Fink D, Frigiola A, Cullen S. Postcardiotomy syndrome: Recurrent cardiac tamponade and an exquisite steroid response. BMJ Case Rep 2012; 2012:bcr2012007761.

18. Hoffman M, Fried M, Jabareen F, Vardinon N, Turner D, Burke M, et al. Anti-heart antibodies in postpericardiotomy syndrome: Cause or epiphenomenon? A prospective, longitudinal pilot study. Autoimmunity 2002; 35:241-5.

19. Köhler I, Saraiva PJ, Wender OB, Zago AJ. Behavior of inflammatory markers of myocardial injury in cardiac surgery: Laboratory correlation with the clinical picture of postpericardiotomy syndrome. Arq Bras Cardiol 2003; 81:279-90.

20. Lehto J, Kiviniemi TO, Gunn J, Mustonen P, Airaksinen J, Biancari $\mathrm{F}$, et al. Occurrence of postpericardiotomy syndrome admissions: A population-based registry study. Ann Med 2016; 48:28-33. 
21. Patel RC, Goyal H, Shah Al, Ghali JK. Wearing the mask of STelevation myocardial infarction: Postpericardiotomy syndrome. Am J Emerg Med 2015; 33:1115.e5-7.

22. Preston I, O'Brien A. Clues to an elusive effusion. Postpericardiotomy syndrome. Postgrad Med 2001; 109:131-2.

23. Sevuk U, Baysal E, Altindag R, Yaylak B, Adiyaman MS, Ay N, et al. Role of diclofenac in the prevention of postpericardiotomy syndrome after cardiac surgery. Vasc Health Risk Manag 2015; 11:373-8.

24. Sevuk U, Baysal E, Altindag R, Yaylak B, Adiyaman MS, Ay N, et al. Role of methylprednisolone in the prevention of postpericardiotomy syndrome after cardiac surgery. Eur Rev Med Pharmacol Sci 2016; 20:514-9.

25. Sievers B, Brandts B, Moon JC, Pennell DJ, Trappe HJ. Cardiovascular magnetic resonance of imminent cardiac tamponade due to postpericardiotomy syndrome. Int J Cardiol 2003; 91:241-4.

26. Syros G, Maysky M. High-pressure loculated pericardial effusion in postpericardiotomy syndrome. Circulation 2012; 125:2677-8

27. Vijarnsorn C, Winijkul G, Laohaprasitiporn D, Chungsomprasong $P$, Chanthong $\mathrm{P}$, Durongpisitkul $\mathrm{K}$, et al. Postoperative fever and major infections after pediatric cardiac surgery. J Med Assoc Thai 2012; 95:761-70.

28. Wendelin G, Fandl A, Beitzke A. High-dose intravenous immunoglobulin in recurrent postpericardiotomy syndrome. Pediatr Cardiol 2008; 29:463-4.

29. Wan S, LeClerc JL, Vincent JL. Inflammatory response to cardiopulmonary bypass: Mechanisms involved and possible therapeutic strategies. Chest 1997; 112:676-92.

30. De Scheerder I, Wulfrank D, Van Renterghem L, Sabbe L, Robbrecht D, Clement D, et al. Association of anti-heart antibodies and circulating immune complexes in the postpericardiotomy syndrome. Clin Exp Immunol 1984; 57:423-8.

31. Erlich J, Paz Z. Postpericardial injury syndrome: An autoimmune phenomenon. Clin Rev Allergy Immunol 2010; 38:156-8.
32. Kocazeybek B, Erentürk S, Calýk MK, Babacan F. An immunological approach to postpericardiotomy syndrome occurrence and its relation with autoimmunity. Acta Chir Belg 1998; 98:203-6.

33. Engle MA, Zabriskie JB, Senterfit LB, Tay DJ, Ebert PA. Immunologic and virologic studies in the postpericardiotomy syndrome. J Pediatr 1975; 87:1103-8.

34. Webber SA, Wilson NJ, Junker AK, Byrne SK, Perry A, Thomas EE, et al. Postpericardiotomy syndrome: no evidence for a viral etiology. Cardiol Young 2001; 11:67-74.

35. Chhabra L, Chaubey VK. Predictors of postpericardiotomy syndrome. Am J Emerg Med 2015; 33:1322.

36. Snefjellå N, Lappegård KT. Development of post-pericardiotomy syndrome is preceded by an increase in pro-inflammatory and a decrease in anti-inflammatory serological markers. J Cardiothorac Surg 2012; 7:72.

37. Finkelstein Y, Shemesh J, Mahlab K, Abramov D, Bar-EI Y, Sagie $A$, et al. Colchicine for the prevention of post-pericardiotomy syndrome. Herz 2002; 27:791-4.

38. Horneffer PJ, Miller RH, Pearson TA, Rykiel MF, Reitz BA, Gardner TJ. The effective treatment of postpericardiotomy syndrome after cardiac operations. A randomized placebocontrolled trial. J Thorac Cardiovasc Surg 1990; 100:292-6.

39. Raatikka M, Pelkonen PM, Karjalainen J, Jokinen EV. Recurrent pericarditis in children and adolescents: Report of 15 cases. J Am Coll Cardiol 2003; 42:759-64.

40. Wamboldt R, Bisleri G, Glover B, Haseeb S, Tse G, Liu T, et al. Primary prevention of post-pericardiotomy syndrome using corticosteroids: A systematic review. Expert Rev Cardiovasc Ther 2018; 16:405-12.

41. Wei L, MacDonald TM, Walker BR.Taking glucocorticoids by prescription is associated with subsequent cardiovascular disease. Ann Intern Med 2004; 141:764-70.

42. Duarte JH. Interventional cardiology: Colchicine therapy prevents postpericardiotomy syndrome but not postoperative atrial fibrillation. Nat Rev Cardiol 2014; 11:620.

......... 